\title{
Synthesis, Antimicrobial and Antioxidant Activities of Sulfone Linked Bis Heterocycles-Pyrazolyl Oxadiazoles and Pyrazolyl Thiadiazole
}

\author{
Venkatapuram Padmavathi, ${ }^{*}$ Sanapalli NAgi Reddy, and Konda Mahesh \\ Department of Chemistry, Sri Venkateswara University; Tirupati-517 502, India. \\ Received July 12, 2009; accepted September 14, 2009; published online September 24, 2009
}

\begin{abstract}
A new class of bis heterocycles-sulfone linked pyrazolyl oxadiazoles and thiadiazoles were developed from $Z$-styrylsulfonylacetic acid. The pyrazolyl thiadiazoles exhibited excellent antimicrobial activity whereas pyrazolyl oxadiazoles displayed good antioxidant activity.
\end{abstract}

Key words Z-styrylsulfonylacetic acid; pyrazolyl oxadiazole; pyrazolyl thiadiazole; antimicrobial activity; antioxidant property

Five membered heterocycles natural as well as synthetic are important class of compounds due to their varied biological properties. Pyrazoles show a wide variety of pharmacological effects including anti-inflammatory, ${ }^{1)}$ antiobesity ${ }^{2)}$ alcohol dehydrogenase inhibitory ${ }^{3)}$ and phosphodiesterase inhibitory ${ }^{4)}$ activities. Some bis pyrazoline derivatives are also found with antimicrobial activity. ${ }^{5}$ Huisgen's 1,3-dipolar cycloaddition is a versatile method to synthesize five membered nitrogen heterocycles. $\left.{ }^{6}\right)$ Recent synthesis of pyrazoles via 1,3-dipolar cycloaddition includes reaction of nitrile imines and activated olefins ${ }^{7,8)}$ or enamines, ${ }^{9,10)}$ hydrazones and nitroolefins, ${ }^{11,12)}$ diazocompounds and activated olefins ${ }^{13-17)}$ and azomethine imines and alkynes. ${ }^{18)} 1,3,4-$ Thiadiazole nucleus constitutes the active part of several biologically active compounds including antibacterial, ${ }^{19-21)}$ antimycotic, ${ }^{22,23)}$ and anti-inflammatory agents. ${ }^{24-26)}$ There are a large number of methods for the synthesis of 2,5-disubstituted 1,3,4-thiadiazoles. The most universal is two-stage method consisting of acylation of thiosemicarbazide using carboxylic acid chlorides and subsequent cyclization of the intermediate acylthiosemicarbazides in the presence of various dehydrating agents viz., sulfuric acid, phosphorus oxychloride, benzoyl chloride and acetyl chloride. ${ }^{27)}$ In addition, several 1,3,4-oxadiazole derivatives exhibit significant antibacterial $^{28-32)}$ and anti-inflammatory activities. ${ }^{33-35)}$ One of the popular methods for the synthesis of 1,3,4-oxadiazoles involves cyclization of diacylhydrazines prepared by the reaction of acyl chlorides and hydrazine. Several cyclodehydrating agents such as $\mathrm{Et}_{2} \mathrm{O} \cdot \mathrm{BF}_{3}{ }^{36)}$ 1,1,1,3,3,3-hexamethyldisilazane, ${ }^{37)}$ triflic anhydride, ${ }^{38)}$ phosphorus pentoxide, ${ }^{39)}$ polyphosphoric acid $^{40)}$ thionyl chloride, ${ }^{41,42)}$ phosphorus oxychloride $^{43)}$ and sulfuric acid ${ }^{44)}$ have been used. Recently we have reported the synthesis, antimicrobial and cytotoxic activities of 1,3,4-oxadiazoles and 1,3,4-thiadiazoles. ${ }^{45}$ ) In continuation of our interest on the chemical and pharmacological properties of sulfone linked bis heterocycles, we report herein the synthesis, antimicrobial and antioxidant activities of pyrazolyl oxadiazoles and thiadiazoles.

\section{Chemistry}

The starting material Z-styrylsulfonyl acetic acid $\mathbf{3}$ was obtained via the reaction of phenylacetylene with mercaptoacetic acid followed by oxidation (Chart 1). ${ }^{46)}$ The reaction of $\mathbf{3}$ with differently substituted benzoic acid hydrazides in the presence of phosphorus oxychloride afforded 2-aryl-5((styrylsulfonyl)methyl)-1,3,4-oxadiazole (4). Compound 4 was treated with two fold excess thiourea in tetrahydrofuran. The reaction mixture indicated two spots on TLC which were separated and identified as 2-aryl-5-((styrylsulfonyl)methyl)1,3,4-thiadiazole (5) as major product apart from $\mathbf{4}$ as minor one. The ${ }^{1} \mathrm{H}-\mathrm{NMR}$ spectra of $\mathbf{4 a}$ and $\mathbf{5 a}$ displayed two doublets at $6.52,6.48\left(\mathrm{H}_{\mathrm{A}}\right)$ and $7.30,7.34 \mathrm{ppm}\left(\mathrm{H}_{\mathrm{B}}\right)$ for the olefin protons. A singlet at 4.55, $4.49 \mathrm{ppm}$ was observed in both the compounds which was assigned to methylene protons in addition to signals due to aromatic protons. The coupling constant value $J=11.7 \mathrm{~Hz}$, indicated the cis geometry. The ${ }^{13} \mathrm{C}$ NMR spectra of $\mathbf{4 a}$ and $\mathbf{5 a}$ exhibited signals at 50.8, 48.7 $\left(\mathrm{SO}_{2} \mathrm{CH}_{2}\right), 130.2,130.4\left(\mathrm{C}-\mathrm{H}_{\mathrm{A}}\right), 145.0,142.3\left(\mathrm{C}-\mathrm{H}_{\mathrm{B}}\right), 156.7$, 156.8 (C-5), and $165.3,164.4 \mathrm{ppm}(\mathrm{C}-2)$, respectively. The olefin moiety present in $\mathbf{4}$ and $\mathbf{5}$ was used to develop pyrazoline ring by 1,3-dipolar cycloaddition of diazomethane. Treatment of $\mathbf{4}$ and $\mathbf{5}$ with diazomethane in the presence of catalytic amount of $\mathrm{Et}_{3} \mathrm{~N}$ at -20 to $-15^{\circ} \mathrm{C}$ for $40 \mathrm{~h}$ gave a solid which was identified as 2-( $\left(4^{\prime}, 5^{\prime}\right.$-dihydro- $4^{\prime}$-phenyl1'- $H$-pyrazol-3'-ylsulfonyl)methyl)-5-aryl-1,3,4-oxadiazole (6) and 2-((4',5'-dihydro-4' -phenyl- $1^{\prime}-H$-pyrazol-3' - ylsulfonyl)methyl)-5-aryl-1,3,4-thiadiazole (7) (Chart 2). The ${ }^{1} \mathrm{H}$ NMR spectra of 6a and 7a exhibited an AMX splitting pattern for pyrazoline ring protons at 4.49, $4.47\left(\mathrm{H}_{\mathrm{A}}\right), 4.08,4.17$ $\left(\mathrm{H}_{\mathrm{M}}\right)$ and $3.69,3.61 \mathrm{ppm}\left(\mathrm{H}_{\mathrm{X}}\right)$ respectively, in addition to the signals of methylene and aromatic protons. The observed coupling constant values $J_{\mathrm{AM}}=11.9,12.6 \mathrm{~Hz}, J_{\mathrm{AX}}=6.1$, $6.6 \mathrm{~Hz}, J_{\mathrm{MX}}=11.0,11.5 \mathrm{~Hz}$ indicated that $\mathrm{H}_{\mathrm{A}}, \mathrm{H}_{\mathrm{M}}$ are $c i s, \mathrm{H}_{\mathrm{A}}$, $\mathrm{H}_{\mathrm{X}}$ are trans and $\mathrm{H}_{\mathrm{M}}, \mathrm{H}_{\mathrm{X}}$ are geminal. The compounds 6 and 7 on oxidation with chloranil in xylene gave the corresponding aromatized products, 2-((4'-phenyl-1' $H$-pyrazol-3'-ylsulfonyl)methyl)-5-aryl-1,3,4-oxadiazole (8) and 2-((4'phenyl-1' $H$-pyrazol-3' -ylsulfonyl)methyl)-5-aryl-1,3,4-thiadiazole (9) (Chart 2). The disappearance of AMX splitting pattern and the appearance of a singlet in the downfield region, merged with aromatic protons confirmed their formation. The ${ }^{13} \mathrm{C}-\mathrm{NMR}$ spectra of $\mathbf{8 a}$ and $\mathbf{9 a}$ exhibited signals at 52.3, $49.8\left(\mathrm{SO}_{2} \mathrm{CH}_{2}\right), 134.9,133.2\left(\mathrm{C}-4^{\prime}\right), 139.2,139.4$

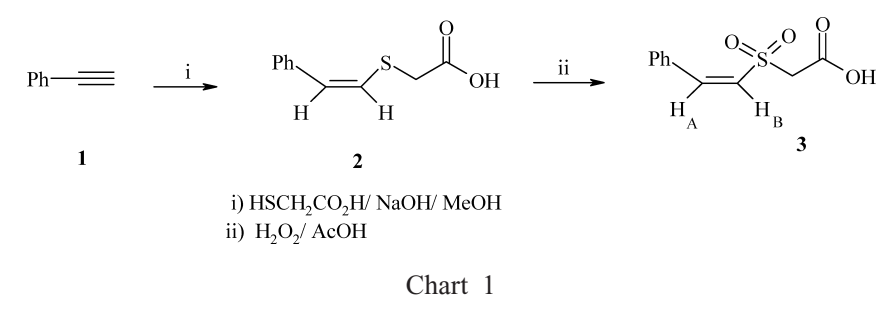



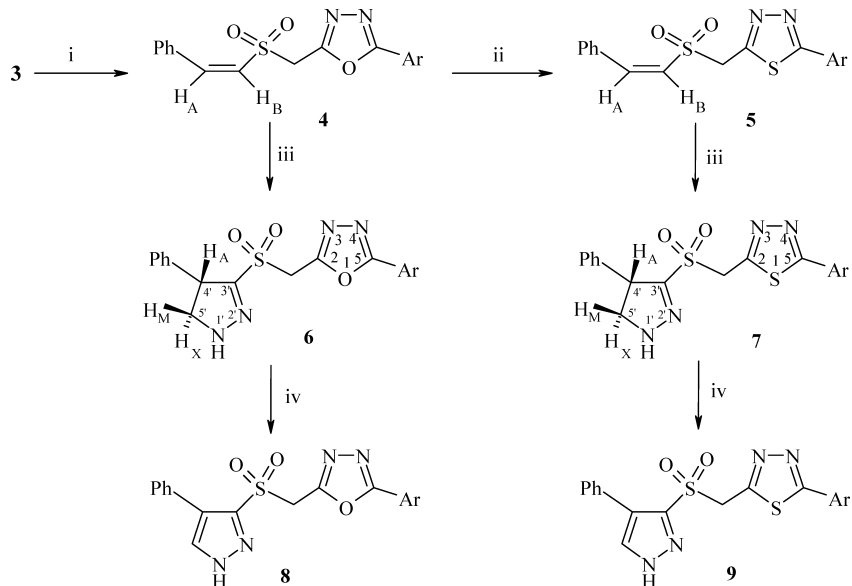

i) $\mathrm{ArCONHNH} H_{2} / \mathrm{POCl}_{3} /$ reflux

ii) $\mathrm{H}_{2} \mathrm{NCSNH}_{2} / \mathrm{THF}$

iii) $\mathrm{CH}_{2} \mathrm{~N}_{2} / \mathrm{Et}_{3} \mathrm{~N} /-20$ to $-15^{\circ} \mathrm{C} / 40-48 \mathrm{~h}$

iv) Chloranil/ Xylene

Chart 2

(C-5'), 149.1, 148.9 (C-3'), 158.7, 157.9 (C-5), 163.9, $164.1 \mathrm{ppm}(\mathrm{C}-2)$, besides signals due to aromatic carbons.

Antimicrobial Testing The compounds 6-9 were tested for antimicrobial activity at two different concentrations 100 and $200 \mu \mathrm{g} / \mathrm{ml}$. The antibacterial activity was screened against Staphylococcus aureus, Bacillus subtilis (Gram-positive bacteria) and Escherichia coli, Klebsiella pneumoniae (Gram-negative bacteria) on nutrient agar plates at $37^{\circ} \mathrm{C}$ for $24 \mathrm{~h}$ using chloramphenicol as reference drug. The compounds were also evaluated for their antifungal activity against Fusarium solani, Curvularia lunata and Aspergillus niger using ketoconazole as standard drug. Fungi cultures were grown on potato dextrose agar medium (PDA) at $25^{\circ} \mathrm{C}$ for $3 \mathrm{~d}$. The spore suspension was adjusted to $10^{6}$ pores $/ \mathrm{ml}$ at a $\mathrm{mg} / \mathrm{ml}$ concentration by the Vincent and Vincent method. ${ }^{47)}$

The results of the compounds of preliminary antibacterial testing are shown in Table 1 . The results revealed that the

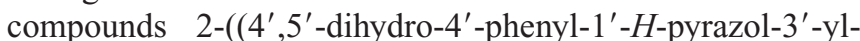
sulfonyl)methyl)-5-aryl-1,3,4-thiadiazole (7) and 2-((4'phenyl-1'H-pyrazol-3' -ylsulfonyl)methyl)-5-aryl-1,3,4-thiadiazole (9) exhibited high activity $(17-38 \mathrm{~mm})$ on both Gram-positive and Gram-negative bacteria. In fact, compounds $7 \mathbf{c}$ and $9 \mathbf{c}$ showed pronounced activity $(30-38 \mathrm{~mm})$ towards Gram-positive bacteria. The compounds 2-((4'phenyl-1' - H-pyrazol-3' -ylsulfonyl)methyl)-5-aryl-1,3,4-oxadiazole (8) displayed moderate activity towards Gram-positive bacteria $(16-22 \mathrm{~mm})$. On the other hand, 2-((4',5'-dihydro-4' -phenyl-1' - H-pyrazol-3' -ylsulfonyl)methyl)-5-aryl1,3,4-oxadiazole (6) exhibited least activity against both bacteria. All the test compounds inhibited the spore germination of tested fungi $A$. niger, $F$. solani and $C$. lunata. Results of the investigation presented in Table 2 revealed that all the compounds except $\mathbf{6}$ showed relatively high inhibitory effect on $F$. solani and $C$. lunata than on $A$. niger. The compounds 7c and 9c displayed high activity.

The minimum inhibitory concentration (MIC) values were determined as the lowest concentration that completely inhibited the visible growth of the microorganisms (Table 3).
Table 1. The in Vitro Antibacterial Activity of 6-9

\begin{tabular}{|c|c|c|c|c|c|}
\hline \multirow{3}{*}{ Compound } & \multirow{3}{*}{$\begin{array}{l}\text { Concen- } \\
\text { tration } \\
(\mu \mathrm{g} / \mathrm{ml})\end{array}$} & \multicolumn{4}{|c|}{ Zone of inhibition (mm) } \\
\hline & & \multicolumn{2}{|c|}{$\operatorname{Gram}(+) v e$} & \multicolumn{2}{|c|}{$\operatorname{Gram}(-)$ ve } \\
\hline & & S. aureus & B. subtilis & E. coli & K. pneumoniae \\
\hline \multirow[t]{2}{*}{$6 a$} & 100 & 10 & 12 & 7 & - \\
\hline & 200 & 14 & 14 & 9 & 8 \\
\hline \multirow[t]{2}{*}{$6 \mathbf{b}$} & 100 & 8 & 10 & - & - \\
\hline & 200 & 11 & 13 & - & - \\
\hline \multirow[t]{2}{*}{$6 c$} & 100 & 9 & 12 & 8 & - \\
\hline & 200 & 12 & 14 & 10 & - \\
\hline \multirow[t]{2}{*}{$7 a$} & 100 & 24 & 23 & 21 & 23 \\
\hline & 200 & 25 & 27 & 26 & 24 \\
\hline \multirow[t]{2}{*}{$7 \mathbf{b}$} & 100 & 19 & 19 & 17 & 18 \\
\hline & 200 & 22 & 23 & 24 & 22 \\
\hline \multirow[t]{2}{*}{$7 \mathrm{c}$} & 100 & 32 & 30 & 25 & 23 \\
\hline & 200 & 34 & 32 & 26 & 25 \\
\hline \multirow[t]{2}{*}{$8 \mathbf{8}$} & 100 & 17 & 16 & 16 & 14 \\
\hline & 200 & 19 & 20 & 18 & 17 \\
\hline \multirow[t]{2}{*}{$8 b$} & 100 & 15 & 16 & 14 & 12 \\
\hline & 200 & 19 & 21 & 17 & 16 \\
\hline \multirow[t]{2}{*}{$8 \mathrm{c}$} & 100 & 18 & 19 & 16 & 15 \\
\hline & 200 & 21 & 22 & 18 & 19 \\
\hline \multirow[t]{2}{*}{ 9a } & 100 & 26 & 23 & 23 & 23 \\
\hline & 200 & 31 & 28 & 27 & 25 \\
\hline \multirow[t]{2}{*}{$9 b$} & 100 & 23 & 25 & 22 & 22 \\
\hline & 200 & 25 & 28 & 25 & 24 \\
\hline \multirow[t]{2}{*}{$9 \mathrm{c}$} & 100 & 35 & 36 & 30 & 29 \\
\hline & 200 & 37 & 38 & 32 & 31 \\
\hline \multirow[t]{2}{*}{ Chloramphenicol } & 100 & 35 & 38 & 40 & 42 \\
\hline & 200 & 39 & 41 & 44 & 45 \\
\hline
\end{tabular}

Table 2. The in Vitro Antifungal Activity of $6-9$

\begin{tabular}{|c|c|c|c|c|}
\hline \multirow{2}{*}{ Compound } & \multirow{2}{*}{$\begin{array}{l}\text { Concentration } \\
(\mu \mathrm{g} / \mathrm{ml})\end{array}$} & \multicolumn{3}{|c|}{ Zone of inhibition (mm) } \\
\hline & & F. solani & C. lunata & A. niger \\
\hline \multirow[t]{2}{*}{ 6a } & 100 & 13 & 16 & 12 \\
\hline & 200 & 15 & 19 & 14 \\
\hline \multirow[t]{2}{*}{$6 b$} & 100 & 11 & 14 & 10 \\
\hline & 200 & 13 & 17 & 12 \\
\hline \multirow[t]{2}{*}{$6 c$} & 100 & 15 & 18 & 14 \\
\hline & 200 & 17 & 21 & 16 \\
\hline \multirow[t]{2}{*}{$7 \mathbf{a}$} & 100 & 25 & 26 & 21 \\
\hline & 200 & 28 & 28 & 24 \\
\hline \multirow[t]{2}{*}{$7 \mathbf{b}$} & 100 & 23 & 25 & 21 \\
\hline & 200 & 25 & 26 & 22 \\
\hline \multirow[t]{2}{*}{$7 c$} & 100 & 30 & 32 & 26 \\
\hline & 200 & 32 & 34 & 29 \\
\hline \multirow[t]{2}{*}{$8 \mathbf{a}$} & 100 & 21 & 23 & 19 \\
\hline & 200 & 24 & 26 & 22 \\
\hline \multirow[t]{2}{*}{$8 b$} & 100 & 18 & 17 & 15 \\
\hline & 200 & 21 & 22 & 19 \\
\hline \multirow[t]{2}{*}{$8 c$} & 100 & 24 & 25 & 22 \\
\hline & 200 & 26 & 28 & 24 \\
\hline \multirow[t]{2}{*}{ 9a } & 100 & 33 & 33 & 29 \\
\hline & 200 & 36 & 35 & 32 \\
\hline \multirow[t]{2}{*}{$9 b$} & 100 & 28 & 27 & 26 \\
\hline & 200 & 32 & 33 & 30 \\
\hline \multirow[t]{2}{*}{$9 c$} & 100 & 30 & 36 & 24 \\
\hline & 200 & 32 & 39 & 26 \\
\hline \multirow[t]{2}{*}{ Ketoconazole } & 100 & 38 & 41 & 36 \\
\hline & 200 & 42 & 44 & 39 \\
\hline
\end{tabular}

The structure-antimicrobial activity relationship of the synthesized compounds revealed that the compounds having pyrazoline in combination with oxadiazole (6) exhibited least 
Table 3. Minimum Inhibitory Concentration of Compounds $7 \mathbf{c}$ and 9c

\begin{tabular}{|c|c|c|c|c|c|c|c|}
\hline \multirow{2}{*}{ Compound } & \multicolumn{7}{|c|}{ Minimum inhibitory concentration (MIC), $\mu \mathrm{g} / \mathrm{ml}$} \\
\hline & S. aureus & B. subtilis & E. coli & K. pneumoniae & F. solani & C. lunata & A. niger \\
\hline $7 c$ & 100 & 50 & 200 & 200 & 100 & 100 & 100 \\
\hline $9 \mathrm{c}$ & 25 & 25 & 50 & 50 & 50 & 25 & 50 \\
\hline Chloramphenicol & 6.25 & 6.25 & 6.25 & 12.5 & - & - & - \\
\hline Ketoconazole & - & - & - & - & 12.5 & 6.25 & 6.25 \\
\hline
\end{tabular}

Table 4. Antioxidant Activity of 6-9

\begin{tabular}{ccc}
\hline \hline & \multicolumn{2}{c}{$\%$ Inhibition at $100 \mu \mathrm{M}$} \\
\cline { 2 - 3 } Compound & Nitric oxide method & DPPH method \\
\hline 6a & 69.5 & 70.3 \\
6b & 74.1 & 72.5 \\
6c & 78.5 & 79.3 \\
7a & 45.8 & 46.3 \\
7b & 47.3 & 46.8 \\
7c & 49.4 & 49.7 \\
8a & 74.8 & 75.3 \\
8b & 54.3 & 52.5 \\
8c & 89.6 & 88.4 \\
9a & 46.7 & 46.3 \\
9b & 45.5 & 46.9 \\
9c & 49.9 & 50.5 \\
\hline
\end{tabular}

activity when compared with compounds having pyrazole with oxadiazole (8) and pyrazoline/pyrazole with thiadiazole (7/9) moieties. However, compounds 8 displayed moderate activity. On the other hand compounds 7 and 9 exhibited high activity. The presence of chloro substituent on the aromatic ring enhances the activity of the compounds. The maximum activity was observed with the compounds $\mathbf{7 c}$ and $\mathbf{9 c}$.

Antioxidant Testing The compounds 6-9 were tested for antioxidant property by nitric oxide ${ }^{48,49)}$ and 1,1diphenylpicrylhydrazyl (DPPH) ${ }^{50)}$ methods. The compounds 6a, 6b, 6c, 8a and 8c exhibited high antioxidant activity in both nitric oxide and DPPH methods at $100 \mu \mathrm{M}$ concentration (Table 4).

\section{Conclusion}

A new and novel bis heterocyclic systems pyrazolyl oxadiazoles and thiadiazoles were developed from $Z$-styrylsulfonylacetic acid by appropriate functionalization of acid and olefin groups. The compounds pyrazolyl thiadiazoles exhibited excellent antimicrobial activity, whereas pyrazolyl oxadiazoles showed good antioxidant property.

\section{Experimental}

Melting points were determined in open capillaries on a Mel-Temp apparatus and are uncorrected. The purity of the compounds was checked by TLC (silica gel H, BDH, ethyl acetate/hexane, 1:3). The IR spectra were recorded on a Thermo Nicolet IR 200 FT-IR spectrometer as KBr pellets and the wave numbers were given in $\mathrm{cm}^{-1}$. The ${ }^{1} \mathrm{H}-\mathrm{NMR}$ spectra were recorded in $\mathrm{CDCl}_{3} / \mathrm{DMSO}-d_{6}$ on a Bruker spectrospin operating at $400 \mathrm{MHz}$. The ${ }^{13} \mathrm{C}$ NMR spectra were recorded in $\mathrm{CDCl}_{3} / \mathrm{DMSO}-d_{6}$ on Bruker spectrospin operating at $100 \mathrm{MHz}$. All chemical shifts are reported in $\delta(\mathrm{ppm})$ using TMS as an internal standard. The microanalyses were performed on a PerkinElmer $240 \mathrm{C}$ elemental analyzer. The antioxidant property was carried out by using Shimadzu UV-2450 spectrophotometer. The starting compound Zstyrylsulfonylacetic acid (3) was prepared by the literature procedure. ${ }^{46)}$

General Procedure of Synthesis of 2-Aryl-5-((styrylsulfonyl)methyl)1,3,4-oxadiazole $(4 \mathbf{a}-\mathbf{c}) \quad$ To $Z$-styrylsulfonylacetic acid $(5 \mathrm{mmol})$ and ben- zoic acid hydrazide $(5 \mathrm{mmol}), \mathrm{POCl}_{3}(4 \mathrm{ml})$ was added and heated under reflux for $5-6 \mathrm{~h}$. The excess $\mathrm{POCl}_{3}$ was removed under reduced pressure and the residue was poured onto crushed ice. The resulting precipitate was filtered, washed with saturated sodium bicarbonate solution and then with water, dried and recrystallized from ethanol to get 4 .

2-Phenyl-5-((styrylsulfonyl)methyl)-1,3,4-oxadiazole (4a): White solid, yield $75 \%, \mathrm{mp} 112-114^{\circ} \mathrm{C}$; IR $(\mathrm{KBr}) \mathrm{cm}^{-1}: 1589(\mathrm{C}=\mathrm{N}), 1542(\mathrm{C}=\mathrm{C})$, $1317,1135\left(\mathrm{SO}_{2}\right) ;{ }^{1} \mathrm{H}-\mathrm{NMR}\left(\mathrm{CDCl}_{3}\right) \delta: 4.55\left(\mathrm{~s}, 2 \mathrm{H}, \mathrm{SO}_{2}-\mathrm{CH}_{2}\right), 6.52(\mathrm{~d}, 1 \mathrm{H}$, $\left.\mathrm{H}_{\mathrm{A}}, J=11.7 \mathrm{~Hz}\right), 7.30\left(\mathrm{~d}, 1 \mathrm{H}, \mathrm{H}_{\mathrm{B}}, J=11.7 \mathrm{~Hz}\right), 7.22-7.92(\mathrm{~m}, 10 \mathrm{H}, \mathrm{Ar}-\mathrm{H})$; ${ }^{13} \mathrm{C}-\mathrm{NMR}\left(\mathrm{CDCl}_{3}\right) \delta: 50.8\left(\mathrm{SO}_{2}-\mathrm{CH}_{2}\right), 130.2\left(\underline{\mathrm{C}}-\mathrm{H}_{\mathrm{A}}\right), 145.0\left(\underline{\mathrm{C}}-\mathrm{H}_{\mathrm{B}}\right), 156.7$ (C-5), 165.3 (C-2), 121.8, 126.1, 127.2, 128.5, 130.1, 130.7, 131.5, 136.2 (aromatic carbons).

2-((Styrylsulfonyl)methyl)-5- $p$-tolyl-1,3,4-oxadiazole (4b): White solid, yield $74 \%, \mathrm{mp} 105-107^{\circ} \mathrm{C}$; IR $(\mathrm{KBr}) \mathrm{cm}^{-1}: 1593(\mathrm{C}=\mathrm{N}), 1546(\mathrm{C}=\mathrm{C})$, $1318,1138\left(\mathrm{SO}_{2}\right) ;{ }^{1} \mathrm{H}-\mathrm{NMR}\left(\mathrm{CDCl}_{3}\right) \delta: 2.26\left(\mathrm{~s}, 3 \mathrm{H}, \mathrm{Ar}-\mathrm{CH}_{3}\right), 4.53(\mathrm{~s}, 2 \mathrm{H}$, $\left.\mathrm{SO}_{2}-\mathrm{CH}_{2}\right), 6.54\left(\mathrm{~d}, 1 \mathrm{H}, \mathrm{H}_{\mathrm{A}}, J=11.8 \mathrm{~Hz}\right), 7.31\left(\mathrm{~d}, 1 \mathrm{H}, \mathrm{H}_{\mathrm{B}}, J=11.8 \mathrm{~Hz}\right)$, 7.25-7.94 (m, 9H, Ar-H); ${ }^{13} \mathrm{C}-\mathrm{NMR}\left(\mathrm{CDCl}_{3}\right) \delta: 21.8\left(\mathrm{Ar}-\mathrm{CH}_{3}\right), 51.1$ $\left(\mathrm{SO}_{2}-\mathrm{CH}_{2}\right), 129.6\left(\underline{\mathrm{C}}-\mathrm{H}_{\mathrm{A}}\right), 146.1\left(\underline{\mathrm{C}}-\mathrm{H}_{\mathrm{B}}\right), 156.1(\mathrm{C}-5), 164.8(\mathrm{C}-2), 121.2$, 125.2, 128.2, 128.9, 129.7, 130.9, 131.2, 136.4 (aromatic carbons).

2-( $p$-Chlorophenyl)-5-((styrylsulfonyl)methyl)-1,3,4-oxadiazole (4c): White solid, yield $74 \%$, mp $127-129^{\circ} \mathrm{C}$; IR $(\mathrm{KBr}) \mathrm{cm}^{-1}: 1608(\mathrm{C}=\mathrm{N})$, $1559(\mathrm{C}=\mathrm{C}), 1320,1143\left(\mathrm{SO}_{2}\right) ;{ }^{1} \mathrm{H}-\mathrm{NMR}\left(\mathrm{CDCl}_{3}\right) \delta: 4.58(\mathrm{~s}, 2 \mathrm{H}$, $\left.\mathrm{SO}_{2}-\mathrm{CH}_{2}\right), 6.56\left(\mathrm{~d}, 1 \mathrm{H}, \mathrm{H}_{\mathrm{A}}, J=12.0 \mathrm{~Hz}\right), 7.33\left(\mathrm{~d}, 1 \mathrm{H}, \mathrm{H}_{\mathrm{B}}, J=12.0 \mathrm{~Hz}\right)$, 7.27-7.96 (m, 9H, Ar-H); ${ }^{13} \mathrm{C}-\mathrm{NMR}\left(\mathrm{CDCl}_{3}\right) \delta: 51.2\left(\mathrm{SO}_{2}-\mathrm{CH}_{2}\right), 130.6$ $\left(\underline{\mathrm{C}}-\mathrm{H}_{\mathrm{A}}\right), 145.2\left(\underline{\mathrm{C}}-\mathrm{H}_{\mathrm{B}}\right), 156.9(\mathrm{C}-5), 165.6(\mathrm{C}-2), 121.5,126.3,128.5,129.5$, $130.2,130.6,131.7,138.6$ (aromatic carbons).

General Procedure of Synthesis of 2-Aryl-5-((styrylsulfonyl)methyl)1,3,4-thiadiazole $(5 \mathrm{a}-\mathrm{c})$ In a sealed test tube, a mixture of $\mathbf{4}(5 \mathrm{mmol})$, thiourea $(20 \mathrm{mmol})$ dissolved in tertahydrofuran $(5 \mathrm{ml})$ was taken. The contents were heated at $120-150^{\circ} \mathrm{C}$ in an oil bath for $22-26 \mathrm{~h}$. After the reaction was completed, it was extracted with dichloromethane. The organic layer was washed with water, brine solution and dried over anhydrous $\mathrm{Na}_{2} \mathrm{SO}_{4}$. The resultant solid was recrystallized from methanol to obtain 5 .

2-Phenyl-5-((styrylsulfonyl)methyl)-1,3,4-thiadiazole (5a): White solid, yield $64 \%$, mp $133-135^{\circ} \mathrm{C}$; IR $(\mathrm{KBr}) \mathrm{cm}^{-1}: 1580(\mathrm{C}=\mathrm{N}), 1544(\mathrm{C}=\mathrm{C})$, 1318, $1140\left(\mathrm{SO}_{2}\right) ;{ }^{1} \mathrm{H}-\mathrm{NMR}\left(\mathrm{CDCl}_{3}\right) \delta: 4.49\left(\mathrm{~s}, 2 \mathrm{H}, \mathrm{SO}_{2}-\mathrm{CH}_{2}\right), 6.48(\mathrm{~d}, 1 \mathrm{H}$, $\left.\mathrm{H}_{\mathrm{A}}, J=11.6 \mathrm{~Hz}\right), 7.34\left(\mathrm{~d}, 1 \mathrm{H}, \mathrm{H}_{\mathrm{B}}, J=11.6 \mathrm{~Hz}\right), 7.17-7.92(\mathrm{~m}, 10 \mathrm{H}, \mathrm{Ar}-\mathrm{H})$; ${ }^{13} \mathrm{C}-\mathrm{NMR}\left(\mathrm{CDCl}_{3}\right) \delta: 48.7\left(\mathrm{SO}_{2}-\mathrm{CH}_{2}\right), 130.4\left(\underline{\mathrm{C}}-\mathrm{H}_{\mathrm{A}}\right), 142.3\left(\underline{\mathrm{C}}-\mathrm{H}_{\mathrm{B}}\right), 156.8$ (C-5), 164.4 (C-2), 121.4, 125.2, 128.4, 128.9, 130.1, 130.3, 131.6, 134.5 (aromatic carbons)

2-((Styrylsulfonyl)methyl)-5- $p$-tolyl-1,3,4-thiadiazole $(\mathbf{5 b})$ : White solid, yield $69 \%, \mathrm{mp} 147-149^{\circ} \mathrm{C}$; IR $(\mathrm{KBr}) \mathrm{cm}^{-1}: 1594(\mathrm{C}=\mathrm{N}), 1548(\mathrm{C}=\mathrm{C})$, 1324, $1142\left(\mathrm{SO}_{2}\right) ;{ }^{1} \mathrm{H}-\mathrm{NMR}\left(\mathrm{CDCl}_{3}\right) \delta: 2.23\left(\mathrm{~s}, 3 \mathrm{H}, \mathrm{Ar}-\mathrm{CH}_{3}\right) 4.46(\mathrm{~s}, 2 \mathrm{H}$, $\left.\mathrm{SO}_{2}-\mathrm{CH}_{2}\right), 6.51\left(\mathrm{~d}, 1 \mathrm{H}, \mathrm{H}_{\mathrm{A}}, J=11.8 \mathrm{~Hz}\right), 7.32\left(\mathrm{~d}, 1 \mathrm{H}, \mathrm{H}_{\mathrm{B}}, J=11.8 \mathrm{~Hz}\right)$, 7.19-7.83 (m, 9H, Ar-H); ${ }^{13} \mathrm{C}-\mathrm{NMR}\left(\mathrm{CDCl}_{3}\right) \delta: 21.9\left(\mathrm{Ar}-\mathrm{CH}_{3}\right), 49.3$ $\left(\mathrm{SO}_{2}-\mathrm{CH}_{2}\right), 129.7\left(\underline{\mathrm{C}}-\mathrm{H}_{\mathrm{A}}\right), 145.3\left(\underline{\mathrm{C}}-\mathrm{H}_{\mathrm{B}}\right), 155.6(\mathrm{C}-5), 165.7(\mathrm{C}-2), 121.6$, 123.4, 125.6, 127.5 , 130.4, 130.5, 130.7, 133.7 (aromatic carbons).

2-( $p$-Chlorophenyl)-5-((styrylsulfonyl)methyl)-1,3,4-thiadiazole (5c): White solid, yield $72 \%, \mathrm{mp} 155-157^{\circ} \mathrm{C}$; IR $(\mathrm{KBr}) \mathrm{cm}^{-1}: 1561(\mathrm{C}=\mathrm{C})$, $1603(\mathrm{C}=\mathrm{N}), 1322,1144\left(\mathrm{SO}_{2}\right) ;{ }^{1} \mathrm{H}-\mathrm{NMR}\left(\mathrm{CDCl}_{3}\right) \delta: 4.48(\mathrm{~s}, 2 \mathrm{H}$, $\left.\mathrm{SO}_{2}-\mathrm{CH}_{2}\right), 6.53\left(\mathrm{~d}, 1 \mathrm{H}, \mathrm{H}_{\mathrm{A}}, J=12.0 \mathrm{~Hz}\right), 7.36\left(\mathrm{~d}, 1 \mathrm{H}, \mathrm{H}_{\mathrm{B}}, J=12.0 \mathrm{~Hz}\right)$, 7.23-7.99 (m, 9H, Ar-H); ${ }^{13} \mathrm{C}-\mathrm{NMR}\left(\mathrm{CDCl}_{3}\right) \delta: 48.2\left(\mathrm{SO}_{2}-\mathrm{CH}_{2}\right), 130.7$ $\left(\underline{\mathrm{C}}-\mathrm{H}_{\mathrm{A}}\right), 145.7\left(\underline{\mathrm{C}}-\mathrm{H}_{\mathrm{B}}\right), 147.1(\mathrm{C}-5) 162.8(\mathrm{C}-2), 120.7,126.4,127.7,128.6$, $130.0,130.8,131.9,134.8$ (aromatic carbons).

General Procedure of Synthesis of 2-((4',5'-Dihydro-4'-phenyl-1' $H$ pyrazol-3'-ylsulfonyl)methyl)-5-aryl-1,3,4-oxadiazole $(6 a-c) / 2-\left(\left(4^{\prime}, 5^{\prime}-\right.\right.$ Dihydro-4'-phenyl-1' $H$-pyrazol-3'-ylsulfonyl)methyl)-5-aryl-1,3,4-thiadiazole $(7 \mathbf{a}-\mathbf{c}) \quad$ To a cooled solution of $\mathbf{4} / \mathbf{5}(2.5 \mathrm{mmol})$ in dichloromethane $(10 \mathrm{ml})$, an ethereal solution of diazomethane $(20 \mathrm{ml}, 0.4 \mathrm{M})$ and triethylamine $(0.06 \mathrm{~g})$ were added. The reaction mixture was kept at -20 to $-15^{\circ} \mathrm{C}$ for $40-48 \mathrm{~h}$. The solvent was removed under reduced pressure. The resultant solid was purified by column chromatography (silica gel (BDH) 
60-120 mesh, hexane-ethyl acetate, $4: 1)$.

2-((4',5'-Dihydro-4' -phenyl-1' H-pyrazol-3' -ylsulfonyl)methyl)-5-phenyl1,3,4-oxadiazole (6a): Yellow solid, yield $62 \%, \mathrm{mp} 136-138^{\circ} \mathrm{C}$; IR $(\mathrm{KBr})$ $\mathrm{cm}^{-1}: 3338(\mathrm{NH}), 1582(\mathrm{C}=\mathrm{N}), 1331,1130\left(\mathrm{SO}_{2}\right) ;{ }^{1} \mathrm{H}-\mathrm{NMR}\left(\mathrm{DMSO}-d_{6}\right) \delta$ : $3.69\left(\mathrm{dd}, 1 \mathrm{H}, \mathrm{H}_{\mathrm{X}}, J_{\mathrm{AX}}=6.1 \mathrm{~Hz}, J_{\mathrm{MX}}=11.0 \mathrm{~Hz}\right), 4.74\left(\mathrm{~d}, 1 \mathrm{H}, \mathrm{SO}_{2}-\mathrm{CH}_{2}\right.$, $J=14.6 \mathrm{~Hz}), 4.08\left(\mathrm{dd}, 1 \mathrm{H}, \mathrm{H}_{\mathrm{M}}, J_{\mathrm{AM}}=11.9 \mathrm{~Hz}, J_{\mathrm{MX}}=11.0 \mathrm{~Hz}\right), 4.49(\mathrm{dd}, 1 \mathrm{H}$, $\left.\mathrm{H}_{\mathrm{A}}, J_{\mathrm{AM}}=11.9 \mathrm{~Hz}, J_{\mathrm{AX}}=6.1 \mathrm{~Hz}\right) 5.03\left(\mathrm{~d}, 1 \mathrm{H}, \mathrm{SO}_{2}-\mathrm{CH}_{2}, J=14.6 \mathrm{~Hz}\right), 7.20$ $7.94(\mathrm{~m}, 10 \mathrm{H}, \mathrm{Ar}-\mathrm{H}), 8.87$ (brs, $1 \mathrm{H}, \mathrm{NH}) ;{ }^{13} \mathrm{C}-\mathrm{NMR}\left(\mathrm{DMSO}-d_{6}\right) \delta: 48.6$ $\left(\mathrm{C}-4^{\prime}\right), 51.6\left(\mathrm{SO}_{2}-\mathrm{CH}_{2}\right), 59.1\left(\mathrm{C}-5^{\prime}\right), 149.4\left(\mathrm{C}-3^{\prime}\right), 156.6(\mathrm{C}-5), 165.5(\mathrm{C}-2)$, 123.2, 125.6, 127.5, 129.1, 129.8, 137.2, 138.9 (aromatic carbons). Anal. Calcd for $\mathrm{C}_{18} \mathrm{H}_{16} \mathrm{~N}_{4} \mathrm{O}_{3} \mathrm{~S}$ : C, 58.68; H, 4.38; N, 15.21; Found: C, 58. 81; H, 4.43; N, 15.32 .

2-((4',5'-Dihydro-4' -phenyl-1' $H$-pyrazol-3'-ylsulfonyl $)$ methyl $)-5$ - $p$-tolyl1,3,4-oxadiazole $(\mathbf{6 b})$ : Yellow solid, yield $72 \%, \mathrm{mp} 112-114^{\circ} \mathrm{C}$; IR $(\mathrm{KBr})$ $\mathrm{cm}^{-1}: 3341(\mathrm{NH}), 1592(\mathrm{C}=\mathrm{N}), 1334,1131\left(\mathrm{SO}_{2}\right) ;{ }^{1} \mathrm{H}-\mathrm{NMR}\left(\mathrm{DMSO}-d_{6}\right) \delta$ : $2.32\left(\mathrm{~s}, 3 \mathrm{H}, \mathrm{Ar}-\mathrm{CH}_{3}\right), 3.66\left(\mathrm{dd}, 1 \mathrm{H}, \mathrm{H}_{\mathrm{X}}, J_{\mathrm{AX}}=6.2 \mathrm{~Hz}, J_{\mathrm{MX}}=11.1 \mathrm{~Hz}\right), 4.06$ $\left(\mathrm{dd}, 1 \mathrm{H}, \mathrm{H}_{\mathrm{M}}, J_{\mathrm{AM}}=12.1 \mathrm{~Hz}, J_{\mathrm{MX}}=11.1 \mathrm{~Hz}\right), 4.47\left(\mathrm{dd}, 1 \mathrm{H}, \mathrm{H}_{\mathrm{A}}, J_{\mathrm{AM}}=12.1 \mathrm{~Hz}\right.$, $\left.J_{\mathrm{AX}}=6.2 \mathrm{~Hz}\right), 4.72\left(\mathrm{~d}, 1 \mathrm{H}, \mathrm{SO}_{2}-\mathrm{CH}_{2}, J=14.2 \mathrm{~Hz}\right), 5.04\left(\mathrm{~d}, 1 \mathrm{H}, \mathrm{SO}_{2}-\mathrm{CH}_{2}\right.$, $J=14.2 \mathrm{~Hz}$ ), $7.21-7.85(\mathrm{~m}, 9 \mathrm{H}, \mathrm{Ar}-\mathrm{H}), 8.95$ (brs, $1 \mathrm{H}, \mathrm{NH}) ;{ }^{13} \mathrm{C}-\mathrm{NMR}$ $\left(\mathrm{DMSO}-d_{6}\right) \delta: 21.8\left(\underline{\mathrm{CH}}_{3}-\mathrm{Ar}\right), 47.7\left(\mathrm{C}-4^{\prime}\right), 51.8\left(\mathrm{SO}_{2}-\mathrm{CH}_{2}\right), 58.2\left(\mathrm{C}-5^{\prime}\right)$, $148.6\left(\mathrm{C}-3^{\prime}\right), 157.8(\mathrm{C}-5), 164.6(\mathrm{C}-2), 122.1,127.7,128.3,129.4,130.1$, 137.4, 140.2 (aromatic carbons). Anal. Calcd for $\mathrm{C}_{19} \mathrm{H}_{18} \mathrm{~N}_{4} \mathrm{O}_{3} \mathrm{~S}: \mathrm{C}, 59.67 ; \mathrm{H}$, $4.74 ; \mathrm{N}, 14.65$; Found: C, 59.73; H, $4.68 ; \mathrm{N}, 14.71$

2-((4',5'-Dihydro-4' -phenyl-1' H-pyrazol-3'-ylsulfonyl)methyl)-5- $(p$ chlorophenyl)-1,3,4-oxadiazole (6c): Yellow solid, yield $74 \%$, mp 148 $150{ }^{\circ} \mathrm{C}$; IR $(\mathrm{KBr}) \mathrm{cm}^{-1}: 3343(\mathrm{NH}), 1606(\mathrm{C}=\mathrm{N}), 1336,1134\left(\mathrm{SO}_{2}\right) ;{ }^{1} \mathrm{H}-$ NMR $\left(\right.$ DMSO-d $\left.d_{6}\right) \delta: 3.68\left(\mathrm{dd}, 1 \mathrm{H}, \mathrm{H}_{\mathrm{X}}, J_{\mathrm{AX}}=6.3 \mathrm{~Hz}, J_{\mathrm{MX}}=11.3 \mathrm{~Hz}\right), 4.13$ $\left(\mathrm{dd}, 1 \mathrm{H}, \mathrm{H}_{\mathrm{M}}, J_{\mathrm{AM}}=12.2 \mathrm{~Hz}, J_{\mathrm{MX}}=11.3 \mathrm{~Hz}\right), 4.54\left(\mathrm{dd}, 1 \mathrm{H}, \mathrm{H}_{\mathrm{A}}, J_{\mathrm{AM}}=12.2 \mathrm{~Hz}\right.$, $\left.J_{\mathrm{AX}}=6.3 \mathrm{~Hz}\right), 4.77\left(\mathrm{~d}, 1 \mathrm{H}, \mathrm{SO}_{2}-\mathrm{CH}_{2}, J=14.9 \mathrm{~Hz}\right), 5.06\left(\mathrm{~d}, 1 \mathrm{H}, \mathrm{SO}_{2}-\mathrm{CH}_{2}\right.$, $J=14.9 \mathrm{~Hz}$ ), $7.23-7.98(\mathrm{~m}, 9 \mathrm{H}, \mathrm{Ar}-\mathrm{H}), 8.97$ (brs, $1 \mathrm{H}, \mathrm{NH}) ;{ }^{13} \mathrm{C}-\mathrm{NMR}$ $\left(\mathrm{DMSO}-d_{6}\right) \delta: 48.9\left(\mathrm{C}-4^{\prime}\right), 51.9\left(\mathrm{SO}_{2}-\mathrm{CH}_{2}\right), 59.3\left(\mathrm{C}-5^{\prime}\right), 146.6\left(\mathrm{C}-3^{\prime}\right)$, 158.0 (C-5), 164.8 (C-2), 122.2, 127.9, 128.8, 129.2, 130.2, 137.6, 140.4 (aromatic carbons). Anal. Calcd for $\mathrm{C}_{18} \mathrm{H}_{15} \mathrm{ClN}_{4} \mathrm{O}_{3} \mathrm{~S}: \mathrm{C}, 53.67 ; \mathrm{H}, 3.75 ; \mathrm{N}$, 13.91; Found: C, 53.60; H, 3.82; N, 14.00 .

2-((4',5'-Dihydro-4' -phenyl-1 ' $-H$-pyrazol-3' -ylsulfonyl $)$ methyl $)-5$ phenyl-1,3,4-thiadiazole (7a): Yellow solid, yield $70 \%$, mp $145-147^{\circ} \mathrm{C}$; IR $(\mathrm{KBr}) \mathrm{cm}^{-1}: 3339(\mathrm{NH}), 1583(\mathrm{C}=\mathrm{N}), 1332,1132\left(\mathrm{SO}_{2}\right) ;{ }^{1} \mathrm{H}-\mathrm{NMR}$ (DMSO-d $)_{6} \delta: 3.61\left(\mathrm{dd}, 1 \mathrm{H}, \mathrm{H}_{\mathrm{X}}, J_{\mathrm{AX}}=6.6 \mathrm{~Hz}, J_{\mathrm{MX}}=11.5 \mathrm{~Hz}\right), 4.17(\mathrm{dd}, 1 \mathrm{H}$, $\left.\mathrm{H}_{\mathrm{M}}, J_{\mathrm{AM}}=12.6 \mathrm{~Hz}, J_{\mathrm{MX}}=11.5 \mathrm{~Hz}\right), 4.47\left(\mathrm{dd}, 1 \mathrm{H}, \mathrm{H}_{\mathrm{A}}, J_{\mathrm{AM}}=12.6 \mathrm{~Hz}\right.$, $\left.J_{\mathrm{AX}}=6.6 \mathrm{~Hz}\right), 4.61\left(\mathrm{~d}, 1 \mathrm{H}, \mathrm{SO}_{2}-\mathrm{CH}_{2}, J=14.7 \mathrm{~Hz}\right), 5.15\left(\mathrm{~d}, 1 \mathrm{H}, \mathrm{SO}_{2}-\mathrm{CH}_{2}\right.$, $J=14.7 \mathrm{~Hz}$ ), $7.25-7.84(\mathrm{~m}, 10 \mathrm{H}, \mathrm{Ar}-\mathrm{H}), 8.91$ (brs, $1 \mathrm{H}, \mathrm{NH}) ;{ }^{13} \mathrm{C}-\mathrm{NMR}$ $\left(\mathrm{DMSO}-d_{6}\right) \delta: 48.8\left(\mathrm{C}-4^{\prime}\right), 49.3\left(\mathrm{SO}_{2}-\mathrm{CH}_{2}\right), 59.3\left(\mathrm{C}-5^{\prime}\right), 149.4\left(\mathrm{C}-3^{\prime}\right)$, 157.8 (C-5), 164.7 (C-2), 122.8, 127.7, 128.5, 129.0 129.7, 134.6, 137.2 (aromatic carbons). Anal. Calcd for $\mathrm{C}_{18} \mathrm{H}_{16} \mathrm{~N}_{4} \mathrm{O}_{2} \mathrm{~S}_{2}: \mathrm{C}, 56.23 ; \mathrm{H}, 4.19 ; \mathrm{N}$, 14.57; Found: C, 56.17; H, $4.11 ; \mathrm{N}, 14.63$.

2-((4',5'-Dihydro-4' -phenyl-1'H-pyrazol-3'-ylsulfonyl)methyl)-5-p-tolyl1,3,4-thiadiazole (7b): Yellow solid, yield $66 \%, \mathrm{mp} 156-158^{\circ} \mathrm{C}$; IR $(\mathrm{KBr})$ $\mathrm{cm}^{-1}: 3342(\mathrm{NH}), 1592(\mathrm{C}=\mathrm{N}), 1334,1133\left(\mathrm{SO}_{2}\right) ;{ }^{1} \mathrm{H}-\mathrm{NMR}\left(\mathrm{DMSO}-d_{6}\right) \delta$ : $2.35\left(\mathrm{~s}, 3 \mathrm{H}, \mathrm{Ar}-\mathrm{CH}_{3}\right), 4.64\left(\mathrm{~d}, 1 \mathrm{H}, \mathrm{SO}_{2}-\mathrm{CH}_{2}, J=14.8 \mathrm{~Hz}\right), 4.97(\mathrm{~d}, 1 \mathrm{H}$, $\mathrm{SO}_{2}-\mathrm{CH}_{2}, J=14.8 \mathrm{~Hz}$ ), $3.67\left(\mathrm{dd}, 1 \mathrm{H}, \mathrm{H}_{\mathrm{X}}, J_{\mathrm{AX}}=6.8 \mathrm{~Hz}, J_{\mathrm{MX}}=11.2 \mathrm{~Hz}\right), 4.11$ $\left(\mathrm{dd}, 1 \mathrm{H}, \mathrm{H}_{\mathrm{M}}, J_{\mathrm{AM}}=12.1 \mathrm{~Hz}, J_{\mathrm{MX}}=11.2 \mathrm{~Hz}\right), 4.50\left(\mathrm{dd}, 1 \mathrm{H}, \mathrm{H}_{\mathrm{A}}, J_{\mathrm{AM}}=12.1 \mathrm{~Hz}\right.$, $\left.J_{\mathrm{AX}}=6.8 \mathrm{~Hz}\right), 7.25-7.97(\mathrm{~m}, 9 \mathrm{H}, \mathrm{Ar}-\mathrm{H}), 8.94$ (brs, $\left.1 \mathrm{H}, \mathrm{NH}\right) ;{ }^{13} \mathrm{C}-\mathrm{NMR}$ $\left(\mathrm{DMSO}-d_{6}\right) \delta: 22.1\left(\underline{\mathrm{CH}}_{3}-\mathrm{Ar}\right), 50.2\left(\mathrm{SO}_{2}-\mathrm{CH}_{2}\right), 49.1\left(\mathrm{C}-4^{\prime}\right), 59.4\left(\mathrm{C}-5^{\prime}\right)$, 147.9 (C-3'), 158.1 (C-5), 163.9 (C-2), 124.3, 127.3 128.7, 129.1, 130.2, 137.5, 139.4 (aromatic carbons). Anal. Calcd for $\mathrm{C}_{19} \mathrm{H}_{18} \mathrm{~N}_{4} \mathrm{O}_{2} \mathrm{~S}_{2}:$ C, 57.27; H, 4.55; N, 14.06; Found: C, 57.35; H, 4.49; N, 14.00 .

2-((4',5'-Dihydro-4' -phenyl-1' H-pyrazol-3'-ylsulfonyl)methyl)-5- $(p$ chlorophenyl)-1,3,4-thiadiazole (7c): Yellow solid, yield $73 \%$, mp 172 $174{ }^{\circ} \mathrm{C}$; IR $(\mathrm{KBr}) \mathrm{cm}^{-1}: 3344(\mathrm{NH}), 1602(\mathrm{C}=\mathrm{N}), 1337,1135\left(\mathrm{SO}_{2}\right) ;{ }^{1} \mathrm{H}-$ NMR $\left(\mathrm{DMSO}-d_{6}\right) \delta: 3.69\left(\mathrm{dd}, 1 \mathrm{H}, \mathrm{H}_{\mathrm{X}}, J_{\mathrm{AX}}=6.6 \mathrm{~Hz}, J_{\mathrm{MX}}=11.8 \mathrm{~Hz}\right), 4.19$ $\left(\mathrm{dd}, 1 \mathrm{H}, \mathrm{H}_{\mathrm{M}}, J_{\mathrm{AM}}=12.8 \mathrm{~Hz}, J_{\mathrm{MX}}=11.8 \mathrm{~Hz}\right), 4.49\left(\mathrm{dd}, 1 \mathrm{H}, \mathrm{H}_{\mathrm{A}}, J_{\mathrm{AM}}=12.8 \mathrm{~Hz}\right.$, $\left.J_{\mathrm{AX}}=6.6 \mathrm{~Hz}\right), 4.69\left(\mathrm{~d}, 1 \mathrm{H}, \mathrm{SO}_{2}-\mathrm{CH}_{2}, J=14.4 \mathrm{~Hz}\right), 5.01\left(\mathrm{~d}, 1 \mathrm{H}, \mathrm{SO}_{2}-\mathrm{CH}_{2}\right.$, $J=14.4 \mathrm{~Hz}$ ), $7.26-8.01(\mathrm{~m}, 9 \mathrm{H}, \mathrm{Ar}-\mathrm{H}), 8.96$ (brs, $1 \mathrm{H}, \mathrm{NH}) ;{ }^{13} \mathrm{C}-\mathrm{NMR}$ $\left(\mathrm{DMSO}-d_{6}\right) \delta: 49.6\left(\mathrm{C}-4^{\prime}\right), 50.7\left(\mathrm{SO}_{2}-\mathrm{CH}_{2}\right), 59.7\left(\mathrm{C}-5^{\prime}\right), 148.2\left(\mathrm{C}-3^{\prime}\right)$, 158.3 (C-5), 164.9 (C-2), 122.4, 128.1, 128.9, 129.4, 130.4, 137.7, 140.6 (aromatic carbons). Anal. Calcd for $\mathrm{C}_{18} \mathrm{H}_{15} \mathrm{ClN}_{4} \mathrm{O}_{2} \mathrm{~S}_{2}: \mathrm{C}, 51.61 ; \mathrm{H}, 3.61$; N, 13.37; Found: C, 51.50; H, 3.65; N, 13.47.

General Procedure of Synthesis of 2-((4'-Phenyl-1' $H$-pyrazol-3'-ylsulfonyl)methyl)-5-aryl-1,3,4-oxadiazole $(8 a-c) / 2-\left(\left(4^{\prime}-\right.\right.$ Phenyl-1' $H$-pyrazol$3^{\prime}$-ylsulfonyl)methyl)-5-aryl-1,3,4-thiadiazole $(9 \mathrm{a}-\mathrm{c})$ A solution of $6 / 7$ $(1 \mathrm{mmol})$ and chloranil $(1.4 \mathrm{mmol})$ in xylene $(10 \mathrm{ml})$ was refluxed for 24 $25 \mathrm{~h}$. Then, the reaction mixture was treated with a $5 \% \mathrm{NaOH}$ solution. The organic layer was separated and repeatedly washed with water. It was dried over anhydrous $\mathrm{Na}_{2} \mathrm{SO}_{4}$ and the solvent was removed on a rotary evaporator.
The resultant solid was purified by recrystallization from 2-propanol.

2-((4'-Phenyl-1' H-pyrazol-3'-ylsulfonyl)methyl)-5-phenyl-1,3,4-oxadiazole (8a): Yellow solid, yield 64\%, mp 157-159 ${ }^{\circ} \mathrm{C}$; IR $(\mathrm{KBr}) \mathrm{cm}^{-1}: 3341$ $(\mathrm{NH}), 1584(\mathrm{C}=\mathrm{N}), 1331,1136\left(\mathrm{SO}_{2}\right) ;{ }^{1} \mathrm{H}-\mathrm{NMR}\left(\mathrm{DMSO}-d_{6}\right) \delta: 4.74(\mathrm{~d}, 1 \mathrm{H}$, $\left.\mathrm{SO}_{2}-\mathrm{CH}_{2}, J=14.6 \mathrm{~Hz}\right), 4.98\left(\mathrm{~d}, 1 \mathrm{H}, \mathrm{SO}_{2}-\mathrm{CH}_{2}, J=14.6 \mathrm{~Hz}\right.$ ), 6.52 (br s, $1 \mathrm{H}$, $\mathrm{NH}) 6.84-7.78\left(\mathrm{~m}, 11 \mathrm{H}, \mathrm{C}_{5},-\mathrm{H}, \mathrm{Ar}-\mathrm{H}\right) ;{ }^{13} \mathrm{C}-\mathrm{NMR}\left(\mathrm{DMSO}-d_{6}\right) \delta: 52.3$ $\left(\mathrm{SO}_{2}-\mathrm{CH}_{2}\right), 134.9\left({\mathrm{C}-4^{\prime}}^{\prime}\right), 139.2\left(\mathrm{C}-5^{\prime}\right), 149.1\left(\mathrm{C}-3^{\prime}\right), 158.7(\mathrm{C}-5), 163.9(\mathrm{C}-$ 2), 122.1, 127.6, 128.4, 129.1, 129.8, 137.2, 140.1 (aromatic carbons). Anal. Calcd for $\mathrm{C}_{18} \mathrm{H}_{14} \mathrm{~N}_{4} \mathrm{O}_{3} \mathrm{~S}$ : C, 59.01; H, 3.85; N, 15.29; Found: C, 59.09; H, $3.90 ; \mathrm{N}, 15.35$.

2-((4'-Phenyl-1' H-pyrazol-3' -ylsulfonyl)methyl)-5- $p$-tolyl-1,3,4-oxadiazole (8b): Yellow solid, yield $69 \%$, mp $163-165^{\circ} \mathrm{C}$; IR $(\mathrm{KBr}) \mathrm{cm}^{-1}: 3342$ $(\mathrm{NH}), 1596(\mathrm{C}=\mathrm{N}), 1332,1138\left(\mathrm{SO}_{2}\right) ;{ }^{1} \mathrm{H}-\mathrm{NMR}\left(\mathrm{DMSO}-d_{6}\right) \delta: 2.32(\mathrm{~s}, 3 \mathrm{H}$, $\left.\mathrm{Ar}-\mathrm{CH}_{3}\right), 4.71\left(\mathrm{~d}, 1 \mathrm{H}, \mathrm{SO}_{2}-\mathrm{CH}_{2}, J=14.2 \mathrm{~Hz}\right), 5.04\left(\mathrm{~d}, 1 \mathrm{H}, \mathrm{SO}_{2}-\mathrm{CH}_{2}\right.$, $J=14.2 \mathrm{~Hz}), 6.56(\mathrm{br} \mathrm{s}, 1 \mathrm{H}, \mathrm{NH}), 6.81-7.75\left(\mathrm{~m}, 10 \mathrm{H}, \mathrm{C}_{5^{\prime}}-\mathrm{H}, \mathrm{Ar}-\mathrm{H}\right) ;{ }^{13} \mathrm{C}-$ NMR (DMSO- $\left.d_{6}\right) \delta: 22.5\left(\mathrm{CH}_{3}-\mathrm{Ar}\right), 51.5\left(\mathrm{SO}_{2}-\mathrm{CH}_{2}\right), 135.2\left(\mathrm{C}-4^{\prime}\right), 141.4$ $\left(\mathrm{C}-5^{\prime}\right), 148.7\left(\mathrm{C}-3^{\prime}\right), 157.8$ (C-5), 164.2 (C-2), 122.3, 127.8, 128.6, 128.9, 130.2, 135.4, 138.8 (aromatic carbons). Anal. Calcd for $\mathrm{C}_{19} \mathrm{H}_{16} \mathrm{~N}_{4} \mathrm{O}_{3} \mathrm{~S}: \mathrm{C}$, 59.99; H, 4.24; N, 14.73; Found: C, 60.07; H, 4.30; N, 14.80.

2-((4'-Phenyl-1' H-pyrazol-3' -ylsulfonyl)methyl)-5-( $p$-chlorophenyl)1,3,4-oxadiazole (8c): Yellow solid, yield $72 \%$, mp $181-183^{\circ} \mathrm{C}$; IR $(\mathrm{KBr})$ $\mathrm{cm}^{-1}: 3344(\mathrm{NH}), 1602(\mathrm{C}=\mathrm{N}), 1334,1142\left(\mathrm{SO}_{2}\right) ;{ }^{1} \mathrm{H}-\mathrm{NMR}\left(\mathrm{DMSO}-d_{6}\right) \delta$ : $4.80\left(\mathrm{~d}, 1 \mathrm{H}, \mathrm{SO}_{2}-\mathrm{CH}_{2}, J=14.9 \mathrm{~Hz}\right), 5.06\left(\mathrm{~d}, 1 \mathrm{H}, \mathrm{SO}_{2}-\mathrm{CH}_{2}, J=14.9 \mathrm{~Hz}\right) 6.53$ (br s, $1 \mathrm{H}, \mathrm{NH}), 6.87-7.78\left(\mathrm{~m}, 10 \mathrm{H}, \mathrm{C}_{5^{\prime}}-\mathrm{H}, \mathrm{Ar}-\mathrm{H}\right) ;{ }^{13} \mathrm{C}-\mathrm{NMR}$ (DMSO-d $\left.d_{6}\right)$ $\delta$ : $52.6\left(\mathrm{SO}_{2}-\mathrm{CH}_{2}\right), 135.4\left(\mathrm{C}-4^{\prime}\right), 141.5\left(\mathrm{C}-5^{\prime}\right), 149.7\left(\mathrm{C}-3^{\prime}\right) 158.9(\mathrm{C}-5)$, 164.4 (C-2), 122.5, 127.4, 128.8, 129.5, 130.4, 137.6, 140.5 (aromatic carbons). Anal. Calcd for $\mathrm{C}_{18} \mathrm{H}_{13} \mathrm{ClN}_{4} \mathrm{O}_{3} \mathrm{~S}$ : C, 53.94; H, 3.27; N, 13.98; Found: C, 54.02; H, 3.31; N, 14.07 .

2-((4'-Phenyl-1' H-pyrazol-3'-ylsulfonyl)methyl)-5-phenyl-1,3,4-thiadiazole (9a): Yellow solid, yield $68 \%, \mathrm{mp} 168-170{ }^{\circ} \mathrm{C}$; IR $(\mathrm{KBr}) \mathrm{cm}^{-1}: 3346$ $(\mathrm{NH}), 1587(\mathrm{C}=\mathrm{N}), 1336,1139\left(\mathrm{SO}_{2}\right) ;{ }^{1} \mathrm{H}-\mathrm{NMR}\left(\mathrm{DMSO}-d_{6}\right) \delta: 4.62(\mathrm{~d}, 1 \mathrm{H}$, $\left.\mathrm{SO}_{2}-\mathrm{CH}_{2}, J=14.3 \mathrm{~Hz}\right), 4.89\left(\mathrm{~d}, 1 \mathrm{H}, \mathrm{SO}_{2}-\mathrm{CH}_{2}, J=14.3 \mathrm{~Hz}\right.$ ), 6.55 (br s, $1 \mathrm{H}$, $\mathrm{NH}), 6.76-7.71\left(\mathrm{~m}, 11 \mathrm{H}, \mathrm{C}_{5}, \mathrm{H}, \mathrm{Ar}-\mathrm{H}\right) ;{ }^{13} \mathrm{C}-\mathrm{NMR}$ (DMSO- $\left.d_{6}\right) \delta: 49.8$ $\left(\mathrm{SO}_{2}-\mathrm{CH}_{2}\right), 133.2\left({\mathrm{C}-4^{\prime}}^{\prime}\right), 139.4\left(\mathrm{C}-5^{\prime}\right), 148.9\left(\mathrm{C}-3^{\prime}\right), 157.9(\mathrm{C}-5), 164.1(\mathrm{C}-$ 2), 124.3, 125.7, 126.5, 129.3, 129.9, 137.4, 138.2 (aromatic carbons). Anal. Calcd for $\mathrm{C}_{18} \mathrm{H}_{14} \mathrm{~N}_{4} \mathrm{O}_{2} \mathrm{~S}_{2}$ : C, 56.53; H, 3.69; N, 14.65; Found: C, 56.45; H, $3.74 ; \mathrm{N}, 14.55$.

2-((4'-Phenyl-1' H-pyrazol-3'-ylsulfonyl)methyl)-5-p-tolyl-1,3,4-thiadiazole (9b): Yellow solid, yield $73 \%$, mp $181-183^{\circ} \mathrm{C}$; IR $(\mathrm{KBr}) \mathrm{cm}^{-1}: 3341$ $(\mathrm{NH}), 1595(\mathrm{C}=\mathrm{N}), 1334,1138\left(\mathrm{SO}_{2}\right) ;{ }^{1} \mathrm{H}-\mathrm{NMR}\left(\mathrm{DMSO}-d_{6}\right) \delta: 2.23(\mathrm{~s}, 3 \mathrm{H}$, $\left.\mathrm{Ar}-\mathrm{CH}_{3}\right), 4.67\left(\mathrm{~d}, 1 \mathrm{H}, \mathrm{SO}_{2}-\mathrm{CH}_{2}, J=14.5 \mathrm{~Hz}\right), 4.90\left(\mathrm{~d}, 1 \mathrm{H}, \mathrm{SO}_{2}-\mathrm{CH}_{2}\right.$, $J=14.5 \mathrm{~Hz}), 6.52(\mathrm{brs}, 1 \mathrm{H}, \mathrm{NH}), 6.84-7.76\left(\mathrm{~m}, 10 \mathrm{H}, \mathrm{C}_{5}{ }^{\prime}-\mathrm{H}, \mathrm{Ar}-\mathrm{H}\right) ;{ }^{13} \mathrm{C}-$ NMR (DMSO- $\left.d_{6}\right) \delta: 22.4\left(\underline{\mathrm{CH}}_{3}-\mathrm{Ar}\right), 48.1\left(\mathrm{SO}_{2}-\mathrm{CH}_{2}\right), 134.3\left(\mathrm{C}-4^{\prime}\right), 141.5$ $\left(\mathrm{C}-5^{\prime}\right), 147.9\left(\mathrm{C}-3^{\prime}\right), 159.7$ (C-5), $164.3(\mathrm{C}-2), 122.4,127.9,128.7,129.5$ $130.3,137.5,138.5$ (aromatic carbons). Anal. Calcd for $\mathrm{C}_{19} \mathrm{H}_{16} \mathrm{~N}_{4} \mathrm{O}_{2} \mathrm{~S}_{2}: \mathrm{C}$, 57.56; H, 4.07; N, 14.13; Found: C, 57.63; H, 4.02; N, 14.18.

2-((4'-Phenyl-1' H-pyrazol-3'-ylsulfonyl)methyl)-5-( $p$-chlorophenyl)1,3,4-thiadiazole (9c): Yellow solid, yield 66\%, mp $194-196{ }^{\circ} \mathrm{C}$; IR (KBr) $\mathrm{cm}^{-1}: 3345(\mathrm{NH}), 1604(\mathrm{C}=\mathrm{N}), 1336,1141\left(\mathrm{SO}_{2}\right) ;{ }^{1} \mathrm{H}-\mathrm{NMR}\left(\mathrm{DMSO}-d_{6}\right) \delta$ : $4.72\left(\mathrm{~d}, 1 \mathrm{H}, \mathrm{SO}_{2}-\mathrm{CH}_{2}, J=14.9 \mathrm{~Hz}\right), 5.03\left(\mathrm{~d}, 1 \mathrm{H}, \mathrm{SO}_{2}-\mathrm{CH}_{2}, J=14.9 \mathrm{~Hz}\right)$, 6.58 (br s, $1 \mathrm{H}, \mathrm{NH}), 6.89-7.78\left(\mathrm{~m}, 10 \mathrm{H}, \mathrm{C}_{5^{\prime}}-\mathrm{H}, \mathrm{Ar}-\mathrm{H}\right) ;{ }^{13} \mathrm{C}-\mathrm{NMR}$ (DMSO$\left.d_{6}\right) \delta: 48.7\left(\mathrm{SO}_{2}-\mathrm{CH}_{2}\right), 132.6\left(\mathrm{C}-4^{\prime}\right), 139.7\left(\mathrm{C}-5^{\prime}\right), 148.7\left(\mathrm{C}-3^{\prime}\right) 159.2(\mathrm{C}-5)$, 165.6 (C-5), 125.4 127.2, 128.9, 129.5, 129.7, 134.8, 139.7 (aromatic carbons). Anal. Calcd for $\mathrm{C}_{18} \mathrm{H}_{13} \mathrm{ClN}_{4} \mathrm{O}_{2} \mathrm{~S}_{2}$ : C, 51.86; H, 3.13; N, 13.44; Found: C, 51.78; H, 3.16; N, 13.52.

Antimicrobial Testing The compounds 6-9 were dissolved in DMSO at different concentrations of 100,200 and $800 \mu \mathrm{g} / \mathrm{ml}$.

Antibacterial and Antifungal Assays Preliminary antimicrobial activity of compounds $6-9$ was tested by agar disc-diffusion method. Sterile filter paper discs (6 mm diameter) moistened with the test compound solution in DMSO of specific concentration $100 \mu \mathrm{g}$ and $200 \mu \mathrm{g}$ /disc were carefully placed on the agar culture plates that had been previously inoculated separately with the microorganisms. The plates were incubated at $37^{\circ} \mathrm{C}$ and the diameter of the growth inhibition zones were measured after $24 \mathrm{~h}$ in case of bacteria and after $48 \mathrm{~h}$ in case of fungi.

The MIC's of the compound assays were determined using micro dilution susceptibility method. Chloramphenicol was used as reference antibacterial agent. Ketoconazole was used as reference antifungal agent. The test compounds, chloramphenicol and ketoconazole were dissolved in DMSO at concentration of $800 \mu \mathrm{g} / \mathrm{ml}$. The two-fold dilution of the solution was prepared $(400,200,100, \ldots, 6.25 \mu \mathrm{g} / \mathrm{ml})$. The microorganism suspensions were incubated at $36^{\circ} \mathrm{C}$ for 24 and $48 \mathrm{~h}$ for bacteria and fungi, respectively. The minimum inhibitory concentrations of the compounds were recorded as the lowest concentration of each chemical compound in the tubes with no turbidity 
(i.e., no growth) of inoculated bacteria/fungi.

Antioxidant Testing The compounds 6-9 are tested for antioxidant property by nitric oxide and DPPH methods.

Assay for Nitric Oxide (NO) Scavenging Activity Sodium nitroprusside $(5 \mu \mathrm{M})$ in phosphate buffer $\mathrm{pH} 7.4$ was incubated with $100 \mu \mathrm{M}$ concentration of test compounds dissolved in a suitable solvent (dioxane/methanol) and tubes were incubated at $25^{\circ} \mathrm{C}$ for $120 \mathrm{~min}$. Control experiment was conducted with equal amount of solvent in an identical manner. At intervals, $0.5 \mathrm{ml}$ of incubation solution was taken and diluted with $0.5 \mathrm{ml}$ of griess reagent ( $1 \%$ sulfanilamide, $0.1 \% N$-naphthylethylenediamine dihydrochloride and 2\%o-phosphoric acid dissolved in distilled water). The absorbance of the chromophore formed during diazotization of nitrite with sulfanilamide and subsequent $N$-naphthylethylenediamine dihydrochloride was read at $\lambda 546 \mathrm{~nm}$. The experiment was repeated in triplicate.

Reduction of 1,1-Diphenyl-2-picrylhydrazyl (DPPH) Free Radical (DPPH Method) The nitrogen centered stable free radical 1,1-diphenyl-2 picrylhydrazyl (DPPH) has often been used to characterize antioxidants. It is reversibly reduced and the odd electron in the $\mathrm{DPPH}$ free radical gives a strong absorption maximum at $\lambda 517 \mathrm{~nm}$, which is purple in color. This property makes it suitable for spectrophotometric studies. A radical scaveng ing antioxidant reacts with DPPH stable free radical and converts into 1,1diphenyl-2-picrylhydrazine. The resulting decolorization is stoichiometric with respect to the number of electrons captured. The change in the absorbance produced in this reaction has been used to measure antioxidant properties.

The solutions of test compounds $(100 \mu \mathrm{M})$ were added to DPPH $(100 \mu \mathrm{M})$ in dioxane/methanol. The tubes were kept at an ambient temperature for $20 \mathrm{~min}$ and the absorbance was measured at $\lambda 517 \mathrm{~nm}$. The difference between the test and the control experiments was taken and expressed as the per cent scavenging of the DPPH radical

Acknowledgements The authors are grateful to Council of Scientific and Industrial Research (CSIR), New Delhi, for financial assistance under major research project.

\section{References}

1) Penning T. D., Talley J. J., Bertenshaw S. R., Carter J. S., Collins P. W., Docter S., Graneto M. J., Lee L. F., Malecha J. W., Miyashiro J. M., Rogers R. S., Rogier D. J., Yu S. S., Anderson G. D., Burton E. G., Cogburn J. N., Gregory S. A., Koboldt C. M., Perkins W. E., Seibert K., Veenhuizen A. W., Zhang Y. Y., Isakson P. C., J. Med. Chem., 40 $1347-1365$ (1997).

2) Rinaldi-Carmona M., Barth F., Héaulme M., Shire D., Calandra B., Congy C., Martinez S., Maruani J., Néliat G., Caput D., Ferrara P., Soubrieé P., Breliére J. C., Le Fur G., FEBS Lett., 350, 240-244 (1994).

3) Baud F. J., Bismuth C., Garnier R., Galliot M., Astier A., Maistre G., Soffer M., Clin. Toxicol., 24, 463-483 (1986).

4) Terrett N. K., Bell A. S., Brown D., Ellis P., Bioorg. Med. Chem. Lett., 6, 1819-1824 (1996).

5) Bhat Abdul R., Athar F., Azam A., Eur. J. Med. Chem., 44, 426- 431 (2009).

6) Huisgen R., J. Org. Chem., 41, 403-419 (1976).

7) Conti P., Pinto A., Tamborini L., Rizzo V., De Micheli C., Tetrahedron, 63, $5554-5560$ (2007).

8) Molteni G., ARKIVOC, ii, 224-246 (2007).

9) Donohue S. R., Halldin C., Pike V. W., Tetrahedron Lett., 492789 2791 (2008)

10) Oh L. M., Tetrahedron Lett., 47, 7943 -7946 (2006).

11) Deng X., Mani N. S., Org. Lett., 10, 1307-1310 (2008)

12) Deng X., Mani N. S., Org. Lett., 8, 3505-3508 (2006).

13) Padmavathi V., Jagan Mohan Reddy B., Chandra Obula Reddy B., Padmaja A., Tetrahedron, 61, 2407-2411 (2005).

14) Padmavathi V., Jagan Mohan Reddy B., Venkata Subbaiah D. R. C., New J. Chem., 28, 1479-1483 (2004).

15) Hari Y., Tsuchida S., Sone R., Aoyama T., Synthesis, 2007, 371-375 (2007).

16) Jiang N., Li C. J., Chem. Commun., 2004, 394-395 (2004).
17) Aggarwal V. K., de Vicente J., Bonnert R. V., J. Org. Chem., 68 $5381-5383$ (2003)

18) Komatsu M., Minakata S., Oderaotoshi Y., ARKIVOC, VII, 370-389 (2006).

19) Foroumadi A., Mansouri S., Kiani Z., Rahmani A., Eur. J. Med. Chem., 38, 851-854 (2003).

20) Thomasco L. M., Gadwood R. C., E. Weaver A., Ochoada J. M., Ford C. W., Zurenko G. E., Hamel J. C., Stapert D., Moerman J. K., Schaadt R. D., Agi B. H., Bioorg. Med. Chem. Lett., 13, 4193-4196 (2003).

21) Karaku S., Rollas S., Il Farmaco, 57, 577-581 (2002).

22) Dogan H. N., Duran A., S. Rollas., Sener G., Uysal M. K., Gülen D. Bioorg. Med. Chem., 10, 2893-2898 (2002).

23) Mamolo M. G., Vio L., Banfi E., Il Farmaco, 51, 71 -74 (1996).

24) Schenone S., Brullo C., Bruno O., Bondavalli F., Ranise A., Filippelli W., Rinaldi B., Capuano A., Falcone G., Bioorg. Med. Chem., 14, 1698-1705 (2006)

25) Santagati M., Modica M., Santagati A., Russo F., Amico-Roxas M., Pharmazie, 49, 880-884 (1994).

26) Palaska E., Sahin G., Kelecin P., Durlu N. T., Altinok G., Il Farmaco, 57, 101-107 (2002).

27) Matysiak J., Niewiadomy A., Synth. Commun., 31, 2537-2547 (2001).

28) Sxahin G., Palaska E., Ekizǒglu M., Zalp M. O., Il Farmaco, 57, $539-542$ (2002)

29) Sx. G. Kuc. u kgu zel., E. E. Oruc., Rollas S., Sxahin. F., Ozbek. A., Eur. J. Med. Chem., 37, 197-206 (2002).

30) Macaev F., Rusu G., Bogrebnoi S., Gudima A., Stingaci E., Vlad L., Shvets N., Kandemirli F., Dimoglo A., Reynolds R., Bioorg. Med. Chem., 13, 4842-4850 (2005).

31) Zitouni G. T., Kaplancikli Z. A., Yildiz. M. T., Chevallet P., Kaya D., Eur. J. Med. Chem., 40, 607-613 (2005).

32) Mamolo M. G., Zampieri D., Vio L., Fermeglia M., Ferrone M., Pricl S., Scialino G., Banfi E., Bioorg. Med. Chem., 13, 3797-3809 (2005).

33) Jakubkiene V., Burbuliene M. M., Mekuskiene G., Udrenaite E., Gaidelis G., Vainilavicius P., Il Farmaco, 58, 323-328 (2003).

34) Narayana B., Vijaya Raj K. K., Ashalatha B. V., Kumari N. S., Arch Pharm. (Weinheim), 338, 373-377 (2005).

35) Amir M., Shikla K., Il Farmaco, 39, 535-545 (2004).

36) Tandon V. K., Chhor R. B., Synth. Commun., 31, 1727-1732 (2001).

37) Diana G. D., Volkots D. L., Nitz T. J., Biailly T. R., Long M. A., Vesico N., Aldous A., Pevear D. C., Dukto F. J., J. Med. Chem., 37, 24212436 (1994).

38) Liras S., Allen M. P., Segelstein B. E., Synth. Commun., 30, 437-444 (2000).

39) Carlsen H. J., Jorgensen K. B., J. Heterocycl. Chem., 31, 805-807 (1994).

40) Tully W. R., Cardner C. R., Gillespie R. J., Westwood R., J. Med. Chem., 34, 2060-2067 (1991)

41) Al-Talib M., Tashtoush H., Odeh N., Synth. Commun., 20, $1811-$ 1817 (1990).

42) Kerr N. V., Ott D. G., Hayes F. N., J. Am. Chem. Soc., 82, 186-189 (1960).

43) Theocharis A. B., Alexandrou N. E., J. Heterocycl. Chem., 27, 16851688 (1990).

44) Short F. W., Long L. M., J. Heterocycl. Chem., 6, 707-712 (1969).

45) Padmavathi V., Sudhakar Reddy G., Padmaja A., Kondaiah P., AliShazia., Eur. J. Med. Chem., 44, 2106-2112 (2009).

46) Bhaskar Reddy D., Muralidhar Reddy M., Subbaraju G. V., Indian J. Chem., 34B, 816-822 (1995).

47) Vincent J. C., Vincent H. W., Proc. Soc. Exp. Biol. Merd., 55, 162 164 (1944).

48) Shirwaiker A., Rajendran K., Dinesh Kumar C., Indian J. Exp. Biol., 42, 803-807 (2004)

49) Babu B. H., Shailesh B. S., Paddikala J., Fitotherapia, 72, 272-279 (2001).

50) Kato K., Terao S., Shimamoto N., Hirata M., J. Med. Chem., 31, 793798 (1988) 